INTERNATIONAL ASPECTS OF OVERPOPULATION 


\section{INTERNATIONAL \\ ASPECTS OF \\ OVERPOPULATION}

Proceedings of a Conference held by the South African Institute of International Affairs at Johannesburg

Edited by

JOHN BARRATT and MIGHAEL LOUW 
(C) South African Institute of International Affairs 1972

Softcover reprint of the hardcover nth edition 1972

All rights reserved. No part of this publication may be reproduced or transmitted, in any form or by any means, without permission.

First published 1972 by

THE MACMILLAN PRESS LTD

London and Basingstoke

Associated companies in New York Toronto

Dublin Melbourne Fohannesburg and Madras

Library of Congress catalog card no. 71-1 79498

SBN 333 13121 5

ISBN 978-1-349-01308-1 ISBN 978-1-349-01306-7 (eBook)

DOI 10.1007/978-1-349-01306-7 


\section{Contents}

Foreword

vii

Leif Egeland

Preface

ix

John Barratt

Introduction

$\mathbf{x i}$

Michael H. H. Louw

I Contemporary world demographic trends

I

J. L. Sadie

Discussion

2 World resources, their use and distribution

I5

Willem Brand

Comments

$3^{2}$

John Phillips

Discussion

36

3 World food supplies

39

G. Ugo Papi

Discussion

$5^{6}$

4 The population explosion: Economic implications

$5^{8}$ Joseph J. Spengler

Comments

77

H. M. Robertson

Discussion

82

5 Social aspects of population and its control

H. V. Muhsam

Discussion

92

6 National policies for population control

96 Jean Bourgeois-Pichat

Discussion

IIO

7 International migration

C. A. Price

Discussion 
vi GONTENTS

8 International economic and financial implications of the population explosion Stephen Enke

Discussion

9 The political implications of the population explosion

W. B. Vosloo

Discussion

Io Effective population as a source of international power A. F. K. Organski (with the assistance of Alan Lamborn)

Discussion

I I Population factors in Latin America

J. L. Sadie, Willem Brand, E. S. Munger, M. Nupen

Discussion

I6 I

175

I 79

I2 Population problems in Europe and the Soviet Union Alfred Sauvy

Discussion

I Population factors in the regional politics of Asia Kei Wakaizumi

Discussion

I4 Africa: Economic and other implications of population growth G. M. E. Leistner

Discussion

I5 International action on the population explosion Michael H. H. Louw

Discussion

275

I 6 Conference conclusions

\section{ANNEXURES}

I The population explosion and international relations 28I Background Paper by Professor B. Cockram

2 Opening address

Dr. Anton Rupert

3 Closing address

Douglas Roberts

4 Authors of main papers

5 Panel members and other participants

6 Rapporteurs 


\section{Foreword}

Many aspects of the world's 'population explosion' have been considered at conferences and in published studies, but its impact on the relations between states is one aspect which has not received much serious attention. The South African Institute of International Affairs felt, therefore, that this would be a fruitful theme for a conference of international experts, and that from their deliberations might come a constructive contribution to world thinking and action on this urgent problem affecting all mankind. It is hoped that this report, which contains the main papers and summaries of the discussions, as well as the conclusions reached after nearly a week of deliberations, will make such a contribution.

It was appropriate that this Conference was held in 1970, the centenary of the birth of Jan Christiaan Smuts, because, as the Conference President, Dr. Anton Rupert, said in his opening address, Smuts was 'a man who gave such deep thought to global problems'. The venue of the Conference was Jan Smuts House in Johannesburg, which was established in 1960 as a living memorial to Smuts, and which is the home of the Institute.

The success of the Conference, which is reflected in this report, was due to the efforts and generosity of many people, only some of whom can be mentioned here. The outstanding contributions of the main speakers, rapporteurs and other participants can be judged in the pages which follow. In an annexure appear the names of Corporate Members of the Institute and other South African companies, as well as individuals, without whose support the Conference would not have been possible. A special word of thanks is also due to the Conference President, Dr. Anton Rupert, and to the other officers who assisted in presiding at the working sessions. The advice of Dr. Ben Cockram, who originally conceived the idea of this Conference, of his successor as Smuts Professor of International Relations, Dr. Michael H. H. Louw, and of Professor Jan L. Sadie, was invaluable in the planning of this project.

The Institute and all those who participated in the Conference 
viii FOREWORD

are greatly indebted to the Director, Mr. John Barratt, and his staff, on whose shoulders fell the burden of the preparatory work, which began two years beforehand, and of the organisation of the Conference itself. Their untiring efforts were reflected in the smooth functioning and undoubted success of the Conference.

Mr. Barratt and Professor Louw were responsible as editors for the preparation of these proceedings for publication. In this task they received valuable assistance from Miss Joan Knox and Dr. Denis Worrall.

Finally, mention must be made of the willing co-operation of the University of the Witwatersrand, on whose campus Jan Smuts House is situated.

South African Institute of LEIF EGELAND National Chairman International Affairs 


\section{Preface}

The papers reproduced in this volume are those which were presented at a Conference held at Jan Smuts House in Johannesburg during the week 23 June to I July I970. The theme of the Conference was 'The Impact on International Relations of the Population Explosion', and it was organised by the South African Institute of International Affairs.

The Conference programme was structured so as to allow for consideration firstly of various aspects of rapid population growth, mainly on a national level, leading to a consideration of the international implications, including population factors on a regional level. The order of the programme has been maintained in this volume.

After the presentation of each paper, the topic was discussed by a panel of experts, including the author, and then opened for general discussion. Brief summaries of the main points raised during these discussions are given after each paper. The summaries are based on reports prepared by the Rapporteurs, which were circulated at the Conference. (The names of the Rapporteurs are listed in Annexure 6.)

Information concerning the authors of the papers, including the Background Paper (reproduced in Annexure I), is given in Annexure 4. The names of panel members and other participants appearing in the discussion summaries are listed alphabetically in Annexure 5.

The Conference Conclusions which appear in Chapter 16 were drafted by a representative committee of the Conference, and were then discussed and approved at the closing session, as representing a general consensus among all participants.

The President of the Conference was Dr. Anton Rupert, and the Chairman of the working sessions was Dr. Leif Egeland, National Chairman of the Institute. He was assisted by two Vice-Chairmen: Mr. W. T. Ferguson and Mr. A. J. Karstaedt, who are the Chairmen, respectively, of the Cape Town and Eastern Province Branches of the Institute.

John Barratt

Director, S.A.I.I.A.

Conference Secretary 


\section{Introduction}

\section{MIGHAEL H. H. LOUW}

From the perspective of the seventies, a significant evolution of international relations as an academic discipline may be observed. In the twenties its central concern was world peace, and how this could be ensured through conscious, planned organisational structures and procedures, based on the assumption that peace is indivisible and that the key to its attainment was collective security. Although some of these assumptions proved to have been built on somewhat shaky ground, especially, for example, the idea of collective security, many of them were for want of appropriate substitutes continued in post-war peace machinery. This period, however, is marked by some significant new approaches to world peace, the most important of which were based on the assumption that social and economic factors played an important role in the kind of world situation in which peace could survive and grow. Interest in the consciously planned organisation of world peace and collective security probably did not diminish, but somehow a lessening of confidence in the effectiveness of the United Nations machinery to resolve a number of continuing violent conflicts did become noticeable, and this led to an emerging contemporary belief that world peace is perhaps dependent more upon a fortuitous balance and convergence of the interests and actions of the great powers, than upon deliberate organisational procedures based on the mechanics of voting by unequal states, through which artificial majorities legitimate collective action. This belief that one cannot always 'organise peace' has led, among international organisations, to some subtle but important shifts in their perceptions of contemporary world problems.

Among these the most important development was the emergence, first, of international awareness and concern (an 'international conscience') with broad and long-range, but decisive, conditions and problems in the underlying socio-economic patterns of the world. This conscience, for example, saw the condition of poverty and misery and the widening gap in living standards between the rich 
and poor countries as an unnecessary and intolerable situation in a world where enough natural resources and material wealth were available to eliminate them. Hence the strong belief in 'development' as a solution of some of the ills which could disturb world peace. A comparable belief is expressed in the constructive role which science and technology could play in improving the levels of living in less developed countries, exemplified in the United Nations conference on science and technology in Geneva in 1963 and the subsequent arrangements to continue its work. The obverse side of the technology coin, viz. the tremendous advance of military (especially nuclear) technology, and its obvious attendant dangers of total annihilation, did not go unnoticed either, and the international conscience and problem perception came into operation to bring about, for example, the Test Ban Treaty, the Non-Proliferation Treaty and the Strategic Arms Limitation Talks.

Second, this awareness was accompanied by a perception of the role which international action could and should play in the solution of these problems. This led to the establishment of many institutions and programmes, international, national, official and private, to achieve real and concrete results. The outstanding example here is the United Nations Development Programme, with its intricate web of interrelated organisations, programmes and operations.

Third, this awareness and its attendant role perceptions have tended to become global in scope, not of one or a few countries, or even a region, but of the totality of man's physical environment, i.e. the whole earth, including its associated space. This global and spatial perspective is exemplified in the Test Ban Treaty and the planned United Nations conference on environment in 1972.

It is within this context of an international concern with socioeconomic problem areas, a perception that international action is appropriate and legitimate and of a global total perspective, that the problem of overpopulation should be seen. It was essentially during the period after the Second World War that an awareness developed of the dramatic pace of the rate of world population growth and of depressing implications for levels of living and resources. Normal population growth could still be seen as an element in the socio-economic equation, but population as an 'explosion' of sheer numbers was seen as a problem with serious implications, not only for national levels of living, but also possibly for social and for international peace.

In the process of perception of the problem and of appropriate international action, it soon became clear that the problem of overpopulation was not one involving political issues and differences between nations and that there was no real conflict between states or 
bloc formation caused by the population problem. In fact, some of the strongest proponents of birth control, for example India, were countries with serious overpopulation problems, while some of their opponents had no such problems but opposed some forms of birth control on moral or religious grounds. It was also realised that population growth in the mass was based on the cumulative effects of the single case and the individual act of procreation, and was thus first and foremost a personal and private affair, not subject or amenable to national or international sanctions. As a personal decision, this act was linked to complex psychological, cultural and economic motivations. If it was agreed that one of the most urgent and effective solutions was the reduction of population through birth control (or, to use the more scientific term, 'family planning'), then international and national policies would have to be designed so as to influence and persuade participating individuals to practise birth control. Such persuasion, through family planning campaigns and appeals, would be all the more effective if linked to basic cultural and other motivations and if supported by objective, scientific evidence on the social implications and effects of overpopulation and on the helpful role of contraceptive technology. For this purpose, continuing studies and research on these matters are not only relevant but essential. However, equally important as a parallel activity is the study of the contemporary population problem in its international implications, i.e. its impact on international relations in general, at the present time and in the future, and of the ways in which international action is appropriate or can be made more effective. It was in this context then that the Conference saw its task and the dimensions of this task.

A closer look at this broad theme of overpopulation shows how complex it is and that for understanding it in an international setting, an analysis would be necessary, not only of the factors which bear on overpopulation, but also of the way in which they are interrelated, in terms of cause and effect. Such an analysis would also indicate, from the operational point of view, how the general problem of overpopulation can be subdivided into its constituent problems and how they can be viewed in a national, a regional and an international perspective, and how their solutions would involve differentiated but complementary institutions, procedures and approaches. Many of these problems and their solutions are still changing and developing (for example, contraceptive technology) and the complete perception and identification of problems and the formulation of agreed solutions have not yet reached finality. The problem of overpopulation is therefore both complex and changing.

It would be useful here to indicate briefly some of the major 


\section{INTRODUGTION}

international issues involved in the population problem. Perhaps we should start first with the value dimension, because this constitutes the basic set of premises or the point of departure in individual, national and international decisions on population. Although personal decisions on family size are influenced by cultural factors, there is also the moral issue of the rights of both parents and children.

The right of the parents as individuals and as citizens to procreate, and thus to perpetuate a name, must be considered a fundamental human right. Similarly, the right of an infant to proper care and a decent life must also be considered inviolate. But if the parents have more children than the resources (both personal and national) to ensure their proper care and decent life would permit, thus leading to misery, the two rights come into conflict. This is a moral dilemma, and the only solution seems to lie in the voluntary decision of the parents to plan their families in accordance with reasonable expectations of an adequate standard of living for all. But how, from the international and national points of view, can individuals be persuaded to take decisions appropriate to resolving the larger overall problem of excess population? What moral formula can be helpful here?

A second important issue is how a reasonable quality of life for growing children and adults (which may also be considered one of the 'human rights' of the individual) can be ensured in concrete, tangible terms. These conditions are dependent on the resources of a country to provide them, and these again are dependent on a complex pattern of interacting factors which provide for the production and distribution of material means and the social services which would ensure a reasonable level of living for a tolerable population level, as well as a minimum level for survival for an excessive population. As these conditions of living are normally provided within a national context, they are related to the national resources of a country, the country's capacity to exploit and develop these (a capacity which in turn is related to financial and manpower resources), its economic system and the quality and stability of its government.

A third major issue is finding appropriate formulas for accelerating the development of the poorer countries which are generally also 'overpopulated' in terms of their resources. Their problem is how to raise and to ensure a continuing rise in their standards of living. The wealthier countries are succeeding in this through the development of their technologies and their financial systems, and, in addition, are producing exportable surpluses of food, know-how and capital which could alleviate the misery of the poorer and over- 
populated nations. But the transfer of food, knowledge and capital involves complex problems of trade, intercultural relations and the control and channelling of financial arrangements. There is also the problem of finding appropriate moral formulas, for example, to guide the volume of aid which the wealthier countries should give, the subtle but sensitive difference between development, aid and welfare, and the moral or other obligations of the recipient countries.

Turning now to the operational side, it is clear that for a proper understanding of world population problems a distinction should be made between population as a normal phenomenon and component of a politico-economic society, and population as a problem situation. A certain tolerable or optimal population level (i.e. one based on the ratio between population and resources) in a country is functional, because it provides the basis for manpower for production and for military capability, a market in the economic system and the essential human resources for socio-economic development and for the survival of the national or human species. But when a certain population is either too small to fulfil these functions, or too large for available resources, then it does become a problem. The purpose of this Conference was to focus attention on the problem not of inadequate or tolerable national population, but of excess population on a world scale, and this in terms of its international ramifications. If it is recognised and perceived as a world problem, then its solution requires the development of appropriate policies and programmes, by authorities or organisations on both national and international levels and in both the governmental and private spheres.

Furthermore, such policies and programmes in all four of these contexts would obviously only be effective if they were complementary rather than competitive. This means that the overall problem of the 'population explosion' (to use the more dramatic but currently accepted term) has to be split into sub-problems appropriate for perception and action in the four contexts, i.e. the national, international, governmental and private contexts. It should also be seen in terms of various fields of specialised knowledge applicable to its solution, for example, contraception, food distribution, demography, development, etc., which have to be integrated and thus require an interdisciplinary focus and integrative thinking.

In order to come to grips with the problem of overpopulation, a first requirement would be to get some idea of its dimensions. This would include statistics on world population and its distribution over the globe, the varying structures (age, sex, etc.) in different countries (for example, relative high percentages of old people in some developed countries and high percentages of children and 
young people in most less developed countries), trends, growth patterns, fluctuations and projections for the future, etc. Information is also needed on causes and motivational factors (incentives and disincentives) of population changes, the psychological and cultural aspects of reproduction ('reproduction mores'), population movements (migrations, such as rural-urban or international migrations), food and other resources in relation to population, dietetic patterns, standards of living, etc.

The second step would be to understand the implications and effects of overpopulation. This would include the pressures of population on resources and the resultant lowering of the levels of living (food, diet and social services), the possibilities of social unrest resulting from frustrations and hunger among large masses of population, the over-exploitation of natural resources resulting in their destruction or pollution and the social evils of uncontrolled mass urbanisation. In developing solutions for these problems attention would be drawn to the urgent need for improved industrial and agricultural systems and technology, for the rational exploitation of natural resources and greater social justice in their allocation. Other aspects requiring study are the extent to which food, funds and technological and organisational skills can be transferred from the developed to the less developed countries, and the moral issues of individual, family and national rights and duties regarding procreation.

Third, an accurate and complete perception of overpopulation as a problem would have to be made. This would include formulations, evaluations and decisions regarding its solutions. What would be the specific, realistic and workable solutions for the many subproblems of world overpopulation perceived by the many organisations as their appropriate roles? Who should do what in a total yet complementary pattern of specific action programmes?

In considering these solutions a distinction has to be made between those with short- and those with long-term effects. On the one hand, there are at this moment many areas of overpopulation with malnutrition and poverty, and these require immediate and urgent solutions such as food programmes, employment opportunities and direct social services, such as health and welfare services. But it is essential that such short-term programmes be complemented by long-range programmes, for example, family planning campaigns, mass contraceptive services and a general improvement of the levels of living through economic development and education. These two types of programmes should be carried out not as abstract exercises but within the broad context of an optimum population policy and a national development policy, specifically designed and implemented 
by its government for the unique population situation of each country. International programmes fulfil a different function; they are focused more on the collection and dissemination of information gained through research and through comparative studies in many countries and of the various regions of the world, which is relevant to the formulation of the national population policies of individual countries. International organisations also help to establish, through international discussion, the broad criteria and guide-lines for such policies and programmes.

Because of the nature of its task, the Conference therefore had to concern itself primarily with the wider international dimensions of the problem of world population. It had to examine this problem as it exists today, its implications for the present and the future, and appropriate solutions and their implementation. This exercise thus came to have both an inter-disciplinary and a global focus, and led to an examination of world population in relation to the global environment, a new and possibly more inclusive approach to a complex problem; an approach on which an important contribution has already been made by Harold and Margaret Sprout with their 'ecological triad' (environment, environed organism(s) and interrelationships), which provided the basis for their statement that 'interrelatedness within and between national communities, and the increasing irrelevance of the time-honored distinction between domestic and international questions, constitute major datum points in the ecological perspective on international politics. '* It may be expected that, if further studies of this important problem of our times are to be fruitful, they should be carried out within the context and framework of a world ecology; the parameters of this problem having now shifted to the limits of the globe and of world humanity, thus establishing a truly appropriate challenge to the study of international relations.

* Harold and Margaret Sprout, An Ecological Paradigm for the Study of International Politics (Center of International Studies, Princeton University, 1968) p. 56. 